\title{
Carbamoyl-Phosphate Synthetase I Deficiency
}

National Cancer Institute

\section{Source}

National Cancer Institute. Carbamoyl-Phosphate Synthetase I Deficiency. NCI Thesaurus.

Code C84612.

A congenital disorder caused by mutations in the CPS1 gene. It is characterized by accumulation of ammonia in the blood. Signs and symptoms appear in infancy and include lethargy, seizures, developmental delay and mental disability. 